\title{
PARALISIA FACIAL PERIFERICA, POLINEURITE E DOENÇA DE CHAGAS CRÔNICA
}

\author{
J. FORTES-REGO *
}

Independentemente de uma variação geográfica - fato incontestável - a paralisia facial periférica distribui-se universalmente, apresentando-se freqüentemente como uma das condições mais presentes na prática neurológica ambulatorial 7. A forma predominante estatisticamente é aquela para a qual nenhum fator etiológico é encontrado, chamada "idiopática" ou "de Bell", que pode atingir até 93,62\% de uma casuistica global 4. Como tais epítetos mostram-se por demais desgastados pelo uso inadequado que deles faz a quase totalidade dos autores que se ocupam do assunto, propusemos a substituição de ambos pelo termo isolada tomado aqui em dupla acepção: o acometimento do nervo facial é a única alteração perceptível ao exame neurológico, e não há concomitância de nenhuma outra entidade nosológica - focalizada ou sistêmica de qualquer etiologia 7. Não obstante o absoluto predomínio da forma isolada, dezenas de situações são incriminadas, na literatura especializada, como agentes etiológicos da paralisia facial periférica, que passa a significar, em tais eventualidades, mero sinal neurológico de um contexto sintomático mais amplo. A título de ilustração cabe citar as publicações de Drachman 3, Pope Junior e Kenan 10 e May e Lucente 9, nas quais são enumeradas, respectivamente, 40, 20 e 19 causas distintas de paralisia facial periférica.

As polineurites são outra patologia assaz freqüente na prática neurológica. Duas entidades mórbidas sobressaem aqui como fatores etiológicos: o alcoolismo crônico e o diabete melito. Além destas, muitas outras são responsabilizadas, destacando-se as carências vitamínicas (de causas outras que não o alcoolismo), a insuficiência renal crônica e as colagenoses. Entre nós, e a despeito da grande resistência que ainda é oferecida pela grande maioria dos que lidam com o tema, outro agente etiológico - de enorme importãncia - seria a doença de Chagas crônica, que propicia o surgimento de uma polineurite mista com predomínio do componente motor 6 , o que nos levou a propor uma reclassificação para a tripanosomíase com a inclusão da forma neuritica, subdivisão da forma nervosa 8 .

A forma nervosa da doença de Chagas é quase tão antiga quanto a própria tripanosomíase, desde que nos reportemos aos conceitos originalmente formulados pelo descobridor da moléstia 1 . Já em 1913 Carlos Chagas 2 afirmava

Disciplina de Neurologia do Departamento de Medicina Especializada da Faculdade de Clências da Saúde da Universidade de Brasília: * Professor. 
ser esta doença "a que talvez provoque, em patologia humana, o maior número de afecções orgânicas do sistema nervoso central" e quie, naquela época, possuia "mais de 200 observações desse tipo". Apesar da atenção inicial do ilustre cientista haver-se voltado particularmente para esse aspecto, parece-nos que Vieira 12 situaria bem a questão ao escrever: "No que se refere à sintomatologia (da forma nervosa crônica), queremos chamar a atenção para um ponto que nos parece de importância. Na nossa experiência, as manifestações descritas por Chagas são as menos freqüentes, constituindo quase um achado de exceção". Voltando-se especificamente para a sintomatologia polimorfa, de "cunho neurótico", que freqüentemente é apresentada pelos portadores da forma crônica da moléstia de Chagas, Vieira 11 interpretou-a fisiopatologicamente e reconheceu, nesse conjunto de sintomas aparentemente sem um substrato anatômico, forma clínica bem-individualizada, que denominou "forma neurovegetativa".

O objetivo superior desta publicação é - em relatando o caso de uma paciente que apresentou paralisia facial periférica, polineurite mista e sintomatologia "vaga" aparentemente de natureza psicológica, na vigência de doença de Chagas crônica - contribuir para que se vençam as barreiras erigidas na trajetória para o reconhecimento "oficial” da forma nervosa crônica da doença de Chagas, principalmente no que concerne à subforma neuritica.

\section{OBSERVAÇAO}

FHM (Reg. 214.859), goiana, 42 anos, cabeleireira, casada, encaminhada à Neurologia do Hospital Universitário de Brasilia, em 08.11.83, por médico do Posto de Saúde da Ceilandia (DF), por ser portadora de paralisia facial periférica direita que se instalou subitamente em 03.05.83 e que melhorou apenas parcialmente, apesar de tratamento especializado prontamente instituido (fisioterapia e 25 ampolas de sinaxial). A paralisia foi acompanhada, nos primeiros dias, de leve sensação de "dormência" na hemiface correspondente. Dez dias antes da instalação da paralisia teria apresentado "lesão" no ouvido externo e ouvido médio direitos, acompanhada de dor local e febre, havendo o quadro sido clinicamente interpretado como herpes zoster. Coincidindo com o surgimento da paralisia, passou a sentir "tontura" (sem claro componente vertiginoso), de forma "quase contínua", que se mostrava mais ou menos estacionária no tempo, indiferente a alguns tratamentos médicos ensaiados. Não havia antecedente (pessoal ou familiar) de paralisia facial, diabete, alcoolismo ou epilepsia. O exame neurológico mostrava uma paciente ansiosa, muito queixosa, sem conseguir movimentar o músculo frontal direito e com diminuição da motilidade no orbicular das pálpebras e superciliar correspondentes, sinal dos cílios e abolição do reflexo nasopalpebral; exibia movimentos automáticos associados na metade direita da face ao ocluir os olhos ou quando movimentava a comissura labial direita; havia, ademais, abolição dos reflexos aquileus e hipoestesia tátil "em botas"; o restante do exame estava normal. Exames complementares (apenas os dois que propiciaram alteração) - MG e Imunofluorescência para Chagas reagentes; EHEG com "atividade paroxística lenta de projeção na região temporal anterior esquerda. Tratamento - Exercícios faciais, vitaminas B1, B6 e B12 por via parenteral; ácido nicotínico e fenobarbital, ambos por via oral. Nos três primeiros 
meses houve melhora subjetiva, enquanto o défice motor mostrava-se inalterado. Posteriormente a paciente interrompeu o uso do barbitúrico, dizendo-se pior e pedindo para ser encaminhada a Gastrenterologia por considerar suas queixas oriundas "do estômago".

\section{COMENTARIOS}

$\mathrm{Da}$ análise da observação, três diagnósticos podem ser estabelecidos: (a) paralisia facial periférica direita residual; (b) polineurite mista; (c) sindrome psicofuncional. Estes diagnósticos, contudo, não devem bastar-se, pois nada mais são que expressões topográficas do envolvimento do sistema nervoso a diferentes niveis. Destarte, deve-se buscar um diagnóstico mais geral, que represente a base de tudo, a unidade patológica. Nesse sentido, orientamos o raciocínio para a doença de Chagas, fundamentando-nos nos seguintes pontos: (1) polineurite em paciente procedente de área endêmica, na qual ficaram excluídas as causas mais conhecidas; (2) a paralisia facial não pôde ser catalogada como isolada, pela própria definição desta; o seu caráter sintomático estava reforçado ademais pela evoluçẩo insatisfatórià; dissociá-la etiologicamente da polineurite não pareceria atitude prudente ou lógica, uma vez que as doenças causadoras de uma soem sê-lo também da outra, a exemplo do diabete, de carências vitamínicas e da lepra; (3) as manifestações psíquicas que compunham o quadro clínico ajustavam-se sem esforço à conceituação de sintomatologia de "cunho neurótico", configurando assim a forma "neurovegetativa" da doença de Chagas. Seguiu-se então a etapa laboratorial da investigação, cujos resultados foram confirmatórios. Por oportuno deve-se frisar que mesmo a alteração eletrencefalográfica (que motivou uma prova terapêutica com fenobarbital) possa quiçá ser inserida no quadro geral da doença básica, embora as opiniōes no particular sejam algo desencontradas, como se depreende do estudo de Faria 5. De qualquer modo, o caráter contínuo da tontura e a refratariedade à ação quase sempre eficiente do barbitúrico depõem contra a existência de epilepsia concomitante.

A título de conclusão, calcados na expressão sintomatológica da paciente e na firme convicção da realidade do acometimento do sistema nervoso na tripanosomíase - não só pelos dados ainda algo dispersos da literatura mas principalmente com supedâneo na própria experiência - achamos que o diagnóstico de forma nervosa da doença de Chagas impõem-se no presente caso, traduzindo-se em duas subformas: neuritica (craniana e periférica) e neurovegetativa.

\section{RESUMO}

É apresentado o caso de uma paciente com 42 anos, que exibiu paralisia facial periférica direita, polineurite sensitivo-motora e síndrome psicofuncional. Raciocínio clínico foi engendrado, permitindo a formulação diagnóstica da forma nervosa crônica da doença de Chagas, sendo esta posteriormente confirmada pela investigação laboratorial. 


\section{SUMMARY}

Peripheral facial paralysis, mixed polyneuritis and chronic Chagas' disease.

The author reports the case of a 42-year-old woman who developed right peripheral facial paralysis and mixed polyneuritis in the course of an undiagnosed Chagas' disease. The clinical diagnosis could be confirmed by sorological reactions for Chagas' disease. A likely relationship between chronic Chagas' disease, peripheral facial paralysis and mixed polyneuritis is discussed.

\section{REFERENCIAS}

1. CHAGAS, C. - Aspecto clínico geral da nova entidade mórbida produzida pelo Schizotrypanum cruzi. (Nota prévia.) Brasil-Médico 24:263, 1910.

2. CHAGAS, C. - Les formes nerveuses d'une nouvelle trypanosomiase (Trypanosoma cruzi) inoculé par Tryatoma megista. Nouv. Iconogr. Salpêtrière 26:1, 1913.

3. DRACHMAN, D.A. - Bell's palsy. A neurological point of view. Arch. Otolaryngol. $\quad 89: 147,1969$.

4. EL-FBIARY, H.M. - Facial paralysis: a clinical study of 580 cases. Rheum. Phsy. Med. 11:100, 1971.

5. FARIA, M.A.M. - Associação entre infecção chagásica e síndromes epilépticas. Tese. São Paulo, 1972.

6. FORTES-Rego, J. - Polineuropatias chagásicas. Arq. Neuro-Psiquiat. (São Paulo) $37: 165,1979$.

7. FORTES-RfGO, J. - Paralisia facial periférica isolada: uma condição contnoversa. Diplomata Editora. Brasília, 1981. Distribuído pela Editora Pedagógica e Universitária - E.P.U., São Paulo.

8. FORTES-ReGO, J.; MACEDO, V.O. \& PRATA, A. - Alterações neurologicas periféricas na doença de Chagas crônica. Arq. Neuro-Psiqiłiat. (São Paulo) 38:45, 1980.

9. MAY, M. \& LUCENTE, F.E. - Bell's pals ca:-sed by basal cell carcinoma. J. amer. med. Assoc. 220:1596, 1972.

10. POPE Jr., T.H. \& KENAN, P.D. - Bell's palsy in pregnancy. Arch. Otolaryngol. $89: 930,1969$.

11. VIETRA, C.B. - Manifestações psfquicas na forma crônica da moléstia de Chagas, exemplo de hiperatividade organica. Rev. goiana Med. 10:127, 1964.

12. VIEIRA, C.B. - A forma nervosa crônica da doença de Chagas vista pelo clínico geral. Rev. goiana Med. 12:31, 1966.

13. VIGIRA, C.B. - Manifestaçóes clínicas da desnervação da doença de Chagas. In J. Romeu Cançado (ed.): Doença de Chagas. Belo Horizonte, 1968.

Universidade de Brasilia, Fraculdade de Ciencias da saúde, Departamento de Medicina Especializada, Disciplina de Neurologia - 70910 - Bnasilia, DF - Brasil. 